\title{
Exploration of the Affecting Factors on the Quit Intentions of Online-Game Players in China
}

\author{
Lili Wang ${ }^{1, \mathrm{a}}$, and Bingsheng Yan ${ }^{2}$ \\ ${ }^{1}$ Department of Foreign Languages, Wuhan University of Technology Huaxia College, $430070 \mathrm{Wu}-$ \\ han Hubei, China \\ ${ }^{2}$ Staff Development Institute of China National Tobacco Corporation, 450008 Zhengzhou Henan, \\ China
}

\begin{abstract}
Online-games are products of hedonic information technology. Players' addiction will lead to seriously negative consequences. That how to prevent online-game addiction exclusively becomes a problem concerned by whole society. The purpose of this study is to explore the influence factors and its mechanism that can weaken or even eliminate onlinegame addiction. On the basis of the theory of planned behaviour, anticipated guilt and past behaviour are introduced into the model to explain players' quit intention of online-game. Data collected from 393 online-game players around China mainland indicate that negative attitude, negativesubjective norm and perceived behavioural control significantly affect the quit intention of online-game players, while the anticipated guilt plays a mediator role. Past behaviour can moderate the relations between the anticipated guilt and the quit intention of online-game players. The more the past game behaviour the player owns, the stronger the positive effects of anticipated guilt on game quit intention he/she will harbor. Conclusions are helpful to the intervention of player's game behaviour and strengthen the self-control ability of players.
\end{abstract}

Keywords. online-games; addiction; theory of planning behaviour; anticipated guilt; past behaviour

\section{Introduction}

Online-games can bring pleasure, obsession and social experience to their players (Cai, Cui $\& \mathrm{Li}, 2007)$, it is one of the most popular entertainment products around the world. China's online-game market scale is enormous and developed quickly. According to the data from the China Internet Network Information Center (CNNIC), the number of online-game players has been increased from about one hundred million in 2007 to around three hundred million in 2012, and the average increment of online-game players closes to forty million

\footnotetext{
${ }^{\mathrm{a}}$ Corresponding author: 763695847@qq.com
} 
each year. However, the prosperity of the market cannot cover up the side effects of onlinegames. Lots of negative effects caused by them have drawn too much concern from all walks of the society (He, Guo \& Xiang, 2008; Liu \& Peng, 2009).

Much attention has been paid to the side effects of the game addiction and the Internet addiction quit treatments. Related experts and institutions also arise at the historic moment, however, the treatment measures and their effects are quite controversial (such as electric shock, shutter, et al.). There are a lot of related researches on treating game addiction in the field of medicine and psychology. Those studies are mainly conducted from the perspective of severe addictions (Collins E, Freeman J, 2008; Hsu S H, Wen M H \& Wu M C, 2009). Although some players became completely irrational, most players are rational. To some extent, they are just over-users. In order to eliminate the negative impacts of online-game, more attention should be paid on how to prevent those most players from becoming addicts.

There is few studies on how to regulate the behavior of online-game and prompt some players to reduce or even quit online-game behavior. From the perspective of its nature, the online-game is the product of information technology, which is similar to cigarette and wine. They both provide players with enjoyment and entertainment. However, the difference lies in the content. This study explores the influence factors of online-game quit intention from the perspective of management (especially in marketing and information management).

\section{Background}

Online-games are a kind of entertainment and leisure products based on the medium of the Internet and the terminal of computer. The unique attributes of online-games can satisfy the needs of a variety of players. In general, players can generate flow experience in the process of playing game, which is a kind of enjoyment state that players highly concentrate so that they forget the time and the surrounding environment (Zhang \& Xie, 2008). Specifically, players can obtain a variety of hedonic experiences such as fun, self-efficacy, achievement sense, interpersonal communication, beyond the reality and so on (Zhang \& Xie, 2008). Many players stay in the game beyond their plan in advance and some of them have obsession or even addiction because of excessive use. Therefore, in addition to the game motivation, the negative impact of the game has also received academic attention.

Scholars discussed in details on the harms and causes of online-game addiction. The side effects are coming from three aspects: psychology, physiology and interpersonal relationships. Online-game will lead to certain problems, including negative life consequences, psychological dependence and lack of self-control (Liu M \& Peng W, 2008). Game players often feel lonely. Compared with the non-players, they are lack of confidence and not sociable. They are not satisfied with their life. (Lemmens J S, Valkenburg P M \& Peter, 2011). Participating in the Internet- games excessively can lead to problems in physical health, interpersonal conflict, self-control failure and virtual relationship preferences (Kim M G \& Kim J, 2010).

As a kind of product, the purpose of online-game is to enjoy. Online-game is different from drug. Most of the online-games are legal. It is the players and special natures of the game that cause the issues. Some studies have shown that people with personality traits (lack of self-control, impulsive trait, etc.) tend to be addicted to online-game (Collins E, Freeman J \& Chamarro Premuzic T, 2011). It is demonstrated that a certain of game properties (e.g., curiosity, role play, the sense of belonging, responsibilities and rewards) are also the cause of addiction (Hsu S H, Wen M H\& Wu M C, 2009).

Although the whole society pays much attention to the problems of online-game addiction, addicts are just the minority of huge player community. According to the degree of dependence on online-game, players can be divided into three categories (normal players, 
fanatic and addiction), the real addicts only account for a small part. For the sake of preventing addiction, the former two groups should be strengthened to take prevention and self-control and the latter should be taken treatment (Dai Shenyi, 2011). In view of the online-game addicts, some research put forward the corresponding treatment and its efficacy has been confirmed, such as bupropion slow-releasing online-game addiction (Han D H, Hwang J W, 2010); methylphenidate has the curative effect for addicted children with attention deficit hyperactivity disorder (Han D H, Lee Y S \& Na C, et al, 2009); the scheme of comprehensive psychological intervention system compensation (Gao Wenbin \& Chen Zhiyan, 2006).

For general players and addicts, preventive measures should be taken to prevent their deep game addiction. The researchers have put forward many Suggestions, but empirical study is insufficient (Kuss D \& Griffiths M, 2012). From the perspective of marketing, online-game addiction problem is the excessive use of hedonic products; from the perspective of information management, it is the adoption of information technology with both positive and negative influence. Thus this article attempts to explore how to control, reduce and even quit this controversial product, and also provide advice for the online-game addiction prevention advice by empirical research from the perspective of the theory of planned behaviour (TPB).

\section{Model and hypotheses}

\subsection{Theory of Planning Behaviour}

Theory of Planning Behaviour (TPB) is derived from the Theory of Reasoned Action at the earliest (TRA), TRA Theory holds that beliefs affect the attitude, which affect behaviour tendency. Scholars applied "belief-attitude-intention-behaviour" model of TRA to predict the IT technology acceptance behaviour (Davis F D, Bagozzi R P \& Warshaw P R, 1989). TPB can explain most of the variance of behaviour and intention, so there is a wide range of applications. According to the TRA, behavioural attitude and subjective norm affect the reasoned action by behaviour intention. Behaviour attitude refers to that people evaluate other certain behaviour with overall positive or negative viewpoint, which is good or bad for themselves anticipation; subjective norm manifests that people feel social pressure about whether to take a certain action. Namely, people perceived whether those who are important to him would accept his/her some kind of behaviour. People can only keep limited rationality and consensus often cannot be reached among the attitude, the behavioural intention and the final behaviour. It is inevitable to make irrational action. The reason is that the non-motivation factors can affect behaviour. TPB adds consideration to the perceived behaviour control that can better predict behaviour. Perceived Behavioural Control (PBC) refers to that people perceive if they have had necessary resources and capabilities to take certain behaviour, which is also a kind of control sense of successfully implementing certain behaviour. Individuals will have intense behavioural intention when having stronger self-control on behaviour.

TPB theory is a classical theory in the study of IT technology adoption behaviour. In the studies about the influence factors of adopting mobile service behaviour and the using behaviour of Chinese instant messaging (Wang Y S, Lin H H \& Luarn P, 2006; Lu Y, Zhou

T \& Wang B , 2009), the explanation effect of the TPB model was proved well. Meanwhile, in the study of online-game participation motivation, it was widely proved that TPB model and its components are the important influencing factors of the game participation motivation and adoption intention. Social norms that represented by the positive attitude of colleagues, classmates and friends can promote users to form game loyalty (Hsu C L\& Lu H P, 
2007). It was also confirmed that the three elements of TPB model significantly influence the intention of players participating online-game from a survey conducted online (Lee M C \& Tsai T R, 2010). Furthermore, TPB theory can be applied to a few negative behaviour (e.g., lying, cheating, stealing) that is socially unacceptable and enjoyment action (e.g., smoking, drinking, online-games and so on.) that may bring negative effects to the users as well (Beck L\& Ajzen I, 1991). Conner et al. (2006) found that the negative attitude, subjective norms and perceptual control on non-smoking can reduce smoking intention (Conner M \& Sandberg T, 2006). Positive attitude, subjective norms and perceived behavioural control on alcohol can increase the drinking will (Todd J\& Mullan B, 2002). In the research of the motives of online-games, Xie \& Zhang (2008) found that the subjective norm consisted of the negative attitude of parents and media will reduce game intention.

From the above, it is not difficult to infer that people will promote the formation of the behavioural intention when their attitude towards certain behaviour and subjective norms are all positive and favourable evaluation, otherwise, the behavioural intention will be weakened. And so forth, people naturally want to cut down or stop playing game when they realize that negative influence of online-game. People's life cannot be separated from all kinds of social relations, although some online-game players can find joy in the virtual world, they still can't live without their family, friends and other social relationships independently. Therefore, when players' family, friends and other important social relatives have a negative attitude and evaluation towards their behaviour, they have to reconsider to cut down the game time, or even quit. In addition, the willpower and confidence to avoid the game continuance is not invariably enough for them. When people have a strong confidence on their self-control, they will be more willing to take measures to cut down the game time or avoid inclination. In view of the above, the following three hypotheses will be posited:

H1: Players' negative attitude positively influences online-game quit intention.

H2: Players' negative subjective norm negatively influences online-game quit intention.

H3: Players' perceived behavioural control positively influences online-game quit intention.

\subsection{Anticipated guilt}

Online-game is not an applied product for people; it is just a hedonic one. Extant studies suggest that hedonistic activities can bring people not only happiness, but also sense of guilt (Kivetz R \& Simonson I,2002; Myers J G, Strahilevitz M ,1998), which comes from that they cannot put forward justification when they experience the failure in self-control or perform hedonistic action instead of the target one of self-control(Giner \& Sorolla R, 2001). The sense of guilt is a state of unpleasant emotions which leads to denial of the existing behaviour, status and intention; it can promote all kinds of ethical behaviour and stimulate people to make changes or redemption to unreasonable behaviour as well (Baumeister R F \& Stillwell A M, 1994; Tangney J P, Stuewig J \& Mashek D J, 2007). It is a type of improper behaviour of indulgent enjoyment which derives from excessively participating in online-games. Present research has manifested that the perceived time loss of players in the process of game will cause unfavourable consequences such as sense of guilt and depression (Wood R T A, Griffiths M D \& Parke A, 2007), and common players can take measures to limit their game time in order to avoid any time loss and sense of guilt.

Anticipated emotion is more durable, more strong, more easy to arouse and has more important guidance meanings for the future than experienced one (Baumeister R F, Vohs K D, Dewall C N, et al, 2007; Van Boven L, Ashworth L,2007). The anticipated emotions can promote people to behave reasonably or prevent worse behaviour from them (Sandberg T\& Conner M, 2008). The anticipated emotion can influence actual action through behavioural 
intention. Those people with sense of guilty usually want to make up for the mistakes in order to get forgiveness (Roseman I J, Wiest C \& Swartz T S, 1994). Existing research shows that anticipated emotion has a direct effect on behaviour intention (Taylor $\mathrm{S} \mathrm{A}$, Ishida C \& Wallace D W, 2009). In the study of illegal downloading, anticipated guilt can effectively reduce the behaviour intention (Wang X \& Mcclung S R, 2012). Expectations of guilt can promote rational behaviour and can inhibit unreasonable one as well. Thus players would feel certain negative emotion (such as anticipated guilt) that produces inhibitory effect on the playing game intention when they prepare to play game again. If they want to play online-game, the sense of guilt would restrain their intention. It is logical to conclude that the anticipated guilt of online-game players may have a positive impact on the game quit intention. Based on the above, this paper puts forward the following assumption.

H4: Players' anticipated guilt positively influences the online-game quit intention.

Although TPB can explain the rational behaviour decision, it ignores the role of the emotional process (Conner M \& Armitage C J, 1998). In fact, the emotion is a really important influence factor in the decision-making process (Van der Pligt J, Zeelenberg M, Van Dijk W W, et al, 1997). Empirical studies have shown that adding some emotional variables can improve the explanation efficacy of TPB model. Perugini and Bagozzi (2001) put anticipated emotion into the TPB to extend the model and put forward the MGB model. There are close correlation between attitudes, beliefs, moral judgment and emotion. To some extent, people's attitudes and moral emotions may stimulate concerned emotion. Some moral judgments are their quit intention. To sum up, we can infer that the negative attitude that derives from players or important people around them can stimulate the anticipated guilt prerequisites of guilty sense (Tangney J P, 1999). Therefore, when players are aware of the dangers of the game themselves or feel pressure on the game behaviour which derives from the norms of social environment, they will have a sense of guilty. At the same time, other research confirmed that the mediation effect exists between attitude and behaviour intention (Baron J, 1992; Steenhaut S \&Van Kenhove P, 2006). We think that anticipated guilt should be incorporated in the original TPB model which plays a mediating role. This could help us make a better explanation and prediction of the online-generation, meanwhile, the mediation effect may exist when they are aware of online-game consequences. Accordingly, the following hypotheses are put forward:

H5: Players' negative attitude positively influences anticipated guilt.

H6: Players' negative subjective norms negatively influence anticipated guilt.

H7a: Players' negative attitudes influence online-game quit intention through the mediation effect of anticipated guilt.

H7b: Players' negative subjective norms influence the online-game quit intention through the mediation effect of anticipated guilt.

\subsection{Past behaviour}

The extended TPB model was constructed and widely applied to many different fields because that past behaviour could improve the explanation efficacy when it was put into TPB model. When people constantly repeat a particular behaviour, there will be a considerable influence with respect to their past action on future behaviour tendency (Sutton S, 1994). In the TPB model, the interaction influence that the past behaviour and self-identification generated affects purchase intention (Smith J R, Terry D J, Manstead A S R, et al, 2007). Wang and McClung (2012) found that for people who have illegal downloading experience in the past six months, their anticipated guilt can significantly weaken the future intentions of illegal downloading, however, it is not significant for those who have no same experience (Wang \& Mcclung S R, 2012). 
Since previous studies have proved that the past behaviour moderates the influence of anticipated emotion on behaviour intention (Baumeister R F, Vohs K D, Dewall C N, et al. 2007; Wang \& Mcclung S R, 2012), we believe that the past behaviour moderates the influence of the anticipated guilt on the game quit intention as well. Online-game players of different degrees will vary in terms of psychological mechanism. In general, for players who have experienced online-game for a short time, the anticipated guilt affects the game quit intention weakly; for other players who have played for many years, the similar effect may be stronger than the former. The hypothesized questions as following:

H8: Past behaviours can moderate the effect of anticipated guilt on online-game quit intention. The more the past behaviours have, the stronger the influence of anticipated guilt on game quit intention will be.

According to the above analysis and research hypotheses, we construct the following conceptual model of online-game quit intention based on the theory of the TPB (see Figure 1):

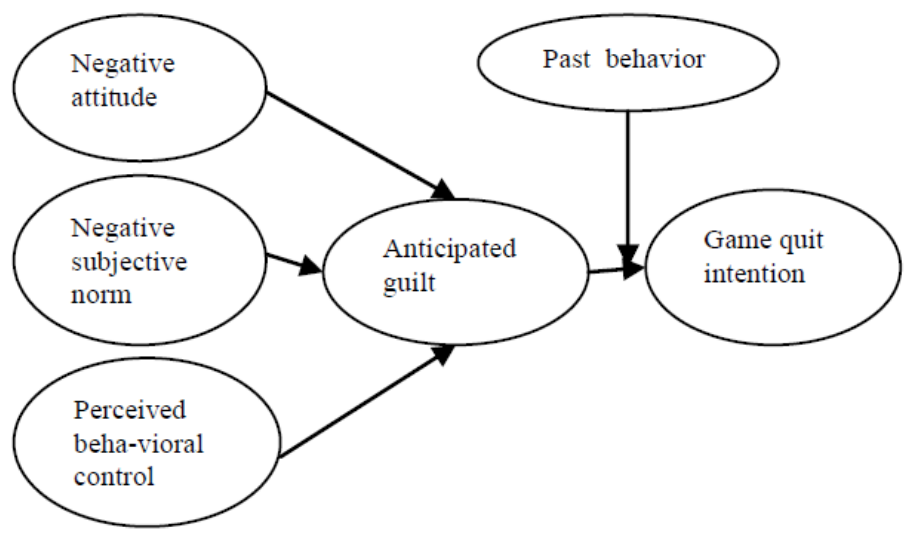

Figure 1. Research model.

\section{Method}

\subsection{Variable measurement and questionnaire design}

This study used sampling survey to collect data, questionnaires mainly include two parts: the scale items and the demographic information. Questionnaire scale adopts 7 points Likert design ("1" means "very disagree", and "7" means "very agree"). The design of the variable dimension are adopted from western authentic literature. In order to guarantee the content validity of the Chinese culture situation, we conducted the process of translation and back translation. The measurement items source and number of constructs are as follows: Attitude (ATT) was assessed by using a four-item self-evaluation developed by Taylor \& Todd (1995). Subjective norms (SN) were measured by using a three-item scale adapted from Hsu \& Chiu (2004). Perceived behavioral control (PBC) was measured by using a four-item scale adapted from Taylor \&Todd (1995). Anticipated guilt (AG) was assessed by using a five-item self-evaluation developed by Wang \& McClung (2012). Past behavior (PB) and Intention (INT) were measured by using a three-item scale adapted from Smith et al. (2007) and Conner et al. (2006). The original questionnaire was discussed and checked out by three doctors and a undergraduate counselor with related major background, and then the pre-test was conducted with 60 undergraduates who have certain online-game 
experience. Eventually, we repeatedly revised and established the final questionnaires according to the feedback of pre-test.

\subsection{Data collection}

It is appropriate that the samples of students are adopted as the research objective, because the literature concerned suggests that student group is the major user of online-game (Coyle J R, Gould S J, Gupta P, et al. 2009). We collected 393 effective student samples with online-game experience through cooperating with a network behaviour research team in Wuhan of China mainland. Typical characteristics of these samples are as follows: 162 $(41.200 \%)$ respondents are male and $231(58.800 \%)$ respondents are female, ranging from 16 to 23 years old; there are 198 people $(50.400 \%)$ under the age of 20 and 195 people $(49.600 \%)$ over the age of 20 ; the average age was 19.050 ; the time that they have played online-game ranges from the least one year up to the longest twelve years. There are 232 people $(68.200 \%)$ within three years of playing online-game and 161 undergraduates $(31.800 \%)$ over three years, and their average Internet age is 3.090 years.

\subsection{Data analysis}

\subsubsection{Measurement model}

Table 1. Factor loading matrix after rotation

\begin{tabular}{llllll}
\hline Factor & 1 & 2 & 3 & 4 & 5 \\
\hline AG1 & 0.890 & 0.010 & 0.112 & 0.181 & 0.087 \\
AG2 & 0.756 & -0.009 & 0.072 & 0.106 & 0.105 \\
AG3 & 0.941 & 0.003 & 0.077 & 0.124 & 0.073 \\
AG4 & 0.925 & 0.006 & 0.096 & 0.140 & 0.098 \\
AG5 & 0.885 & 0.007 & 0.009 & 0.109 & 0.070 \\
INT1 & 0.039 & 0.120 & 0.074 & 0.045 & 0.849 \\
INT2 & 0.162 & 0.055 & 0.059 & 0.068 & 0.889 \\
INT3 & 0.154 & 0.085 & 0.053 & 0.067 & 0.893 \\
PBC1 & 0.004 & 0.913 & 0.058 & -0.002 & 0.056 \\
PBC2 & -0.015 & 0.940 & -0.009 & 0.014 & 0.070 \\
PBC3 & 0.034 & 0.907 & 0.020 & 0.039 & 0.073 \\
PBC4 & -0.012 & 0.910 & 0.019 & 0.024 & 0.087 \\
SN1 & 0.141 & 0.019 & 0.028 & 0.933 & 0.026 \\
SN2 & 0.198 & 0.012 & -0.024 & 0.949 & 0.078 \\
SN3 & 0.237 & 0.043 & 0.046 & 0.917 & 0.093 \\
ATT1 & 0.074 & 0.000 & 0.870 & 0.038 & 0.013 \\
ATT2 & 0.079 & 0.012 & 0.910 & 0.023 & 0.069 \\
ATT3 & 0.073 & 0.025 & 0.879 & -0.033 & 0.055 \\
ATT4 & 0.081 & 0.050 & 0.876 & 0.026 & 0.066 \\
Eigenvalue & 4.079 & 3.398 & 3.178 & 2.718 & 2.395 \\
Variance Explained\% & 21.467 & 17.883 & 16.728 & 14.307 & 12.608 \\
Cumulative variance \% & 21.467 & 39.350 & 56.078 & 70.385 & 82.993 \\
\hline & & & & & \\
\hline
\end{tabular}


The principal component analysis was conducted by varimax rotation. KMO value of 0.840 indicates that the sample data is appropriate for factor analysis. The result of exploratory factor analysis (EFA) suggests that five factors together can explain $82.993 \%$ of the variance. The factor matrix of varimax rotation is shown in Table 2, and the factor loading of each item on the corresponding factor is greater than cross loading of it with other factors. Each item can represent its corresponding factor well; therefore, the scale is confirmed with good validity.

Table 2. Analysis of reliability and validity

\begin{tabular}{llllll}
\hline Construct & Item & Standard loading & CR & AVE & $\alpha$ \\
\hline \multirow{4}{*}{ Attitude (ATT) } & ATT1 & 0.873 & & & \\
& ATT2 & 0.917 & 0.938 & 0.791 & 0.911 \\
& ATT3 & 0.879 & & & \\
Subjective norm (SN) & ATT4 & 0.888 & & & \\
& SN1 & 0.931 & 0.969 & 0.912 & 0.951 \\
& SN2 & 0.973 & & & \\
Perceived behavioural control & SN3 & 0.960 & & & \\
(PBC) & PBC1 & 0.909 & 0.957 & 0.848 & 0.940 \\
& PBC2 & 0.940 & & & \\
& PBC3 & 0.913 & & & \\
& PBC4 & 0.919 & & & \\
Anticipated guilt (AG) & AG1 & 0.924 & \multirow{2}{*}{0.954} & 0.808 & 0.940 \\
& AG2 & 0.778 & & & \\
& AG3 & 0.954 & & & \\
& AG4 & 0.945 & & & \\
\hline
\end{tabular}

Table 3. Correlation coefficient matrix and AVE square root

\begin{tabular}{llllll}
\hline Factor & AVE square root & ATT & SN & PBC & PG \\
\hline ATT & 0.889 & & & & \\
SN & 0.955 & 0.057 & & & \\
PBC & 0.921 & 0.052 & 0.054 & & \\
AG & 0.899 & 0.177 & 0.354 & 0.020 & \\
INT & 0.893 & 0.140 & 0.169 & 0.174 & 0.246 \\
\hline
\end{tabular}

The reliability analysis is applied to test the internal consistency of the scale by calculating Cronbach's $\alpha$-value. There are negative attitude, subjective norm, perceived behavioural control, anticipated guilt and the game quit intention; the coefficients $\alpha$ of them are respectively $0.911,0.951,0.940,0.940$ and 0.874 . It indicates that the five factors have ideal internal consistencies. Convergent validity can be tested by confirmatory factor analysis (CFA) that calculates the standard loading of the scale for all items. Furthermore, the combination reliability (CR) and the average variance extracted (AVE) are obtained according to the standard loading coefficient. Results are shown in Table 3. The standard loading of all items is above 0.800 except AG2 (0.743), CR is higher than 0.900 and the AVEs are 
greater than 0.700 , which indicate that the scale has good convergent validity. The discriminant validity between variables can be distinguished by comparing the square root of AVE of a specific factor with the correlation coefficient of the other factors. See Table 4: The factor's square root of AVE is greater than the correlation coefficient of it and another factor, which indicates the superior discriminant validity of the scale.

It is necessary to test the common method bias because the self-report method is adopted to collect data, and the Hannan's single factor test is a kind of method that leads the process. Results in Table 2 show that five factors from factor analysis in the aggregate explain $82.993 \%$ of the variance, and the variance explained by the first factor is $27.990 \%$ before unimplemented varimax rotation, which manifested that the ratio of variance explained by factor is not too large, thus there doesn't exist the significant problem of the common method bias.

\subsubsection{Structural model}

Four preconditions are needed to verify the structural model, hypotheses and mediation effect: (1) The independent variable significantly affect the dependent variable; (2) the independent variable significantly influences the mediation variable; (3) the mediation variable significantly affects the dependent variable; (4) after controlling mediation variable, the effect of the independent variable on the dependent variable changes will be insignificant or weakened significantly (Baron R M \& Kenny D A,1986). So we take two steps to test the model accordingly. The first step is to build a direct effect model. Negative attitude, negative subjective norm and perceived behavioural control all significantly influence the game quit intention. The path coefficients are respectively $0.130(\mathrm{p}<0.010)$, $0.137(\mathrm{p}<0.010)$ and $0.010(\mathrm{p}<0.001)$. Model fitting index as follows: $\chi^{2}=320.919$, $\mathrm{df}=$ $149, \chi^{2} / \mathrm{df}=2.154, \mathrm{RMSEA}=0.043, \mathrm{GFI}=0.922, \mathrm{CFI}=0.974, \mathrm{NFI}=0.952$, it indicates that the model fitting effect is good. Thus hypotheses H1, H2, H3 are supported and the precondition (1) is met.

The second step includes that:

First, a hypothesis (complete mediation) model is established. Figure 2 shows that the path coefficient of the complete mediation model, namely the effect of negative attitude and negative subjective norm on anticipated guilt, is significant. The path coefficient is 0.219 (p $<0.001)$ and $0.001(\mathrm{p}<0.001)$, the hypotheses H5 and H6 are supported, and precondition (2) can be met. The anticipated guilt can significantly impact on the game quit intention, the path coefficient is $0.196(\mathrm{p}<0.001)$, the hypothesis H4 is supported, and condition (3) can be met as well.

Table 4. Competition model comparison

\begin{tabular}{llllllllll}
\hline MODEL & RMSEA & GFI & CFI & NFI & $\chi^{2}$ & df & $\Delta \chi^{2}$ & $\Delta$ df & $p$ \\
\hline M1 & 0.043 & 0.937 & 0.984 & 0.962 & 253.171 & 148 & & & \\
M2 & 0.042 & 0.937 & 0.984 & 0.963 & 249.800 & 147 & 3.371 & 1 & 0.066 \\
M3 & 0.044 & 0.937 & 0.984 & 0.963 & 250.115 & 147 & 3.056 & 1 & 0.080 \\
M4 & 0.042 & 0.938 & 0.985 & 0.963 & 246.409 & 146 & 6.762 & 2 & 0.034 \\
\hline
\end{tabular}

Note: M1: complete mediation model; M2: partial mediation model1: added: negative attitude $\rightarrow$ quitting game attention, $\beta=0.091(p>0.050)$; M3: partial mediation model2: added: negative subjective norm $\rightarrow$ quitting game attention, $\beta=0.072$ ( $p>0.050)$ M4: partial mediation model3: added: negative attitude $\rightarrow$ quitting game attention, $\beta=0.095(p>0.05)$ added: negative subjective norm $\rightarrow$ quitting game attention, $\beta=0.076(p>0.050)$

Second, hypothesized model (complete mediation model) and three competition model (partial mediation model) are compared and a highly fitting and relative brevity model is 
finally chosen. According to the advice of the Wen et al. (2004), the chi-square criterion is a convenient and reasonable method that can be applied to model comparison. Since the sample size is 393 in our model, the selection of $\alpha=0.0005$ as critical value is appropriate. Table 5 indicates that the fitting degree of partial mediation models 1, 2 and 3 cannot be improved significantly $(\mathrm{p}>0.0005)$ if the negative attitude and negative subjective norm are separately or simultaneously put into the model on the basis of complete mediation model; meanwhile, if we simultaneously add two direct effects of the independent variable to the dependent variable, then the path coefficients become no significant $(p>0.050)$. Thus three competition models are eliminated and the ideal brevity model of complete mediation is chosen. The anticipated guilt can completely mediate the effect of negative attitude, negative subjective norm on game quit intention, Thus precondition (4) can be met and hypotheses $\mathrm{H7a}, \mathrm{H} 7 \mathrm{~b}$ are supported as well.

\subsubsection{Moderating effect test}

Table 5. Regression analysis of past behaviour moderation.

\begin{tabular}{llll}
\hline \multirow{2}{*}{ Variable } & \multicolumn{2}{l}{ Game quit intention } & \\
& $\mathrm{M} 1$ & $\mathrm{M} 2$ & $\mathrm{M} 3$ \\
\hline Gender & $0.156^{* *}$ & $0.153^{* *}$ & $0.171^{* *}$ \\
Age & 0.079 & 0.061 & 0.050 \\
Anticipated guilt & & $0.236^{* *}$ & 0.220 \\
Past behaviour & & 0.034 & 0.065 \\
Anticipated guilt×past behaviour & & & $0.174^{* *}$ \\
Adjusted R2 & 0.021 & 0.073 & 0.099 \\
$\Delta \mathrm{R}^{2}$ & & 0.056 & 0.029 \\
$\mathrm{~F}$ & $5.277^{* *}$ & $8.674^{* *}$ & $9.637^{* *}$ \\
\hline
\end{tabular}

Note: ${ }^{*} p<0.050,{ }^{* *} p<0.010$

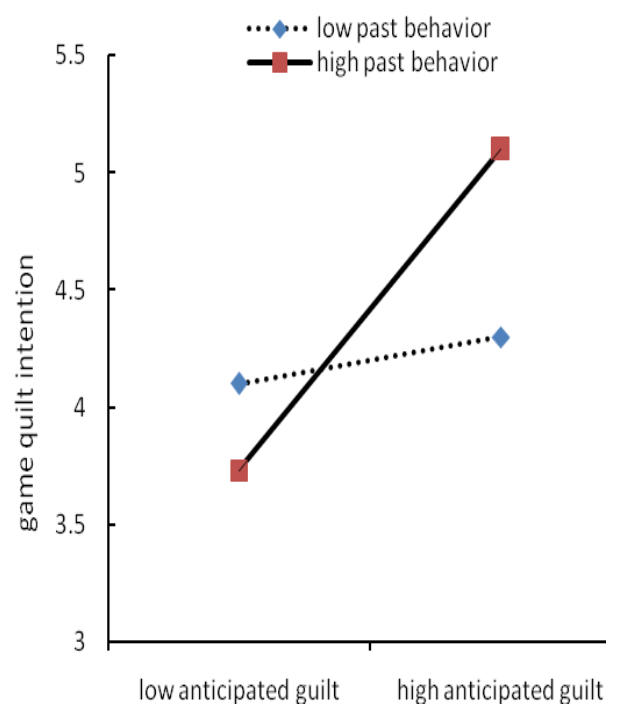

Figure 2. Moderation effect of past behaviour. 
The regression analysis is adopted to test the moderation effect of the past behaviour in the relationship of anticipated guilt and game quit intention. According to the results of Table 6, the past behaviour can significantly moderate the relationship between the anticipated guilt and the game quit intention $(\beta=0.174, \mathrm{p}<0.010)$, and hypothesis $\mathrm{H} 8$ can be supported. The means of past behaviour plus or minus one standard deviation as values of high past behaviour and low past behaviour, and then the moderation effect map can be drawn up. Figure 3 indicates: For players with high past behaviour, the effect of anticipated guilt on onlinegame quilt intention is more significant than that with low past behaviour.

\section{Conclusion and discussion}

Based on the theory of planned behaviour and the theory of anticipated emotion, this study constructed the influence factor model of the game quit intention. Through an empirical analysis of the sampling data of 393 undergraduates, the hypotheses were tested, and at last, the following conclusions were obtained:

The results indicate that the players' negative attitude, the negative subjective norm and the perceived behavioural control can positively influence the game quit intention. Previous literatures have discussed the positive effect of the three important variables in the TPB model on the game adoption and the will of continuance use. They are all based on the positive attitude and evaluation of online-game from players and the important people around them. Previous studies have found that parents and media's negative attitude can lower the negative effects of games participation intention (Zhang \& Xie, 2014). However, there are few systematic studies on how to reduce the players' game intention yet. While our new findings in our research have made some contributions in this aspect: The players' negative attitude and perceived behavioural control positively influence the game quit intention except the negative subjective norms.

In practice, in order to facilitate the online-game players to reduce or eliminate the addiction, the following three pieces of advice are worth to be considered: First, players should set up the correct evaluation and attitude towards online-game. They must remain vigilant to their behaviour that may be out of control and a variety of hedonic experiences (such as joy, immersion and achievement sense) followed with the negative consequences. The stronger players' negative attitude is, the stronger their intrinsic motivation to far away from the game will be. Players' negative attitude towards online-games is equivalent to the body's immune system. Therefore, as a game players or potential players, they should be careful of this kind of hedonic products. Otherwise, that will be very painful and wretched if the external force is adopted to enforce them to give up addiction. Second, some important people (such as parents, teachers and friends) that can significantly influence player's behaviour should have a specifically negative attitude and bring powerful external pressure to them. In fact, those doting parents tend to indulge or acquiesce in this kind of behaviour in the beginning of playing online-game because many Chinese families usually have single-child. The best playmates around players constantly become their intimate friends; even though their teachers obviously oppose the behaviour of playing game, they couldn't interfere with their extracurricular activities. Therefore, it is recommended that parents should fully participate in and supervise their children's game activities. The best measure is to develop other more meaningful hobbies for their children and let them be away from the online-game. Third, individual character is also extraordinarily important to control the game behaviour and the self-control and confidence should be constantly developed and cultivated. However, people often have the deviation of conception owing to undue confidence: They always overestimate themselves. It is not easy that those players indulging game can fight with their intrinsic desire, so their behaviour control ability should be gradually trained as well. 
In the second place, the anticipated guilt has mediation effect to the influence of players' negative attitudes and the negative subjective norms on game quit intention. Being different from previous perspective of IT technology adoption behaviour, this article examined online-game behaviour from the perspective of pleasure-seeking behaviour and the anticipated guilt was introduced to improve the TPB model. The guilty sense indulgent enjoyment can promote the redemption behaviour and the anticipated emotion plays a part between the attitude and the behavioural intention. This study introduced the anticipated guilt to reveal the effect mechanism of internal attitude and the external pressure together on game quit attention. The mediation effect of anticipated emotion was proved that it is an ideal extension for the TPB model incorporating certain emotional variables as well. In reality, the player's negative attitude and the negative evaluation around important figures can motivate their inner feelings of guilt. Under internal and external pressure, the players would expect to the guilty sense, namely, a kind of negative emotion, so that reduce the playing game intention and stimulate the game quit intention.

In the end, the past behaviour moderates the effect of anticipated guilt on game quit intention. For players with more past behaviours, the influence of anticipated guilt on game quit intention is more significant. Therefore, for the sake of promoting the game quit intention, more and more stringent regulatory measures should be taken to motivate their inner feelings of guilt and reinforce their resistance decision to playing online-game for players with more past behaviours.

\section{Limitations and future research directions}

Previous studies have suggested that students are the most important online-game players, at the same time, some studies took the students as the research sample. However, scholars should also investigate the broader game user groups if conditions are met in the future. On one hand, the applicability of the current conclusion can be widely improved; on the other hand, the differences of quitting online-game intention also can be compared with respect to different population characteristics of players. In addition, different kinds of online-game products have different properties, which have not considered in current study yet. Future study should take categorizing online-games into consideration and it may be able to come to a conclusion which is more targeted. At last, cultural circumstance is also an externally assignable cause, and the current study just uses data from China. In fact, how to interfere online-game addiction is a common problem for parents around the world. Further research should focus on players in other cultural circumstances.

\section{References}

1. Baron J.1992. The effect of normative beliefs on anticipated emotions. Journal of personality and social psychology, 63(2): 320-330.

2. Baron R M, \& Kenny D A. 1986. The moderator-mediator variable distinction in social psychological research: conceptual, strategic, and statistical considerations. Journal of personality and social psychology, 51(6): 1173-1182.

3. Baumeister R F, Stillwell A M, \& Heatherton T F. 1994. Guilt: an interpersonal approach. Psychological bulletin, 115(2): 243- 267.

4. Baumeister R F, Vohs K D, \& Dewall C N, et al. 2007. How emotion shapes behavior: Feedback, anticipation, and reflection, rather than direct causation. Personality and Social Psychology Review, 11(2): 167-203.

5. Beck L, \& Ajzen I. 1991. Predicting dishonest actions using the theory of planned behavior. Journal of Research in Personality, 25(3): 285-301. 
6. Cai Yuanyuan, Cui Lijuan, \& Li Xin. 2007. A research on the psychological needs of teenagers online-game behaviors. Psychological Science, (01): 169-172. (in Chinese)

7. Collins E, Freeman J, \& Chamarro-Premuzic T. 2011. Personality traits associated with problematic and non-problematic massively multiplayer online role playing game use. Personality and Individual Differences, 52(2): 133-138.

8. Conner M, \& Armitage C. 1998. Extending the theory of planned behavior: A review and avenues for further research. Journal of applied social psychology, 28(15): 14291464.

9. Conner M, Sandberg T, \& Mcmillan B, et al. 2006. Role of anticipated regret, intentions and intention stability in adolescent smoking initiation. British Journal of Health Psychology, 11(1): 85-101.

10. Coyle J R, Gould S J, \& Gupta P, et al. 2009. "To buy or to pirate": The matrix of music consumers' acquisition-mode decision-making. Journal of Business Research, 62(10): 1031-1037.

11. Davis F D, Bagozzi R P, \& Warshaw P R. 1989. User Acceptance of ComputerTechnology: A Comparison of Two Theoretical Models. Management Science, 35(08): 982-1003.

12. Giner-Sorolla R. 2013. Guilty pleasures and grim necessities: Affective attitudes in dilemmas of self-control. Journal of Personality and Social Psychology, 80(2): 206221.

13. Han D H, Hwang J W, Renshaw P F. 2010. Bupropion sustained release treatment decreases craving for video games and cue-induced brain activity in patients with Internet video game addiction. Experimental and clinical psychopharmacology, 18(4): 297-304.

14. Han D H, Lee Y S, \& Na C, et al. 2009. The effect of methylphenidate on internet video game play in children with attention-deficit/hyperactivity disorder. Comprehensive psychiatry,50(3): 251-256.

15. Hsu C L, \& Lu H P. 2007. Consumer behavior in online-game communities: a motivational factor perspective. Computers in Human Behavior, 23(3): 1642-1659.

16. Hsu M H, \& Chiu C M. 2004. Internet self-efficacy and electronic service acceptance. Decision support systems, 38(3): 369-381.

17. Hsu S H, Wen M H, \& Wu M C. 2009. Exploring user experiences as predictors of MMORPG addiction. Computers \& Education, 53(3): 990-999.

18. Kim M G, \& Kim J. 2010. Cross-validation of reliability, convergent and discriminant validity for the problematic online-game use scale. Computers in Human Behavior, 26(3): 389-398.

19. Kivetz R, \& Simonson I. 2002. Self-control for the righteous: Toward a theory of precommitment to indulgence. Journal of Consumer Research, 29(2): 199-217.

20. Kuss D, \& Griffiths M. 2012. Internet gaming addiction: a systematic review of empirical research. International Journal of Mental Health and Addiction, 10(2): 278-296.

21. Lemmens J S, Valkenburg P M, \& Peter J. 2011. Psychosocial causes and consequences of pathological gaming. Computers in Human Behavior, 27(1):144-152.

22. Myers J G, \& Strahilevitz M. 2013. Donations to charity as purchase incentives: How well they work may depend on what you are trying to sell. Journal of Consumer Research, 24: 434-446.

23. Perugini M, \& Bagozzi R P. 2001. The role of desires and anticipated emotions in goal-directed behaviours: Broadening and deepening the theory of planned behavior. British Journal of Social Psychology, 40(1): 79-98.

24. Sandberg T, \& Conner M. 2008. Anticipated regret as an additional predictor in the theory of planned behaviour: a meta-analysis. The British journal of social psychology/the British Psychological Society, 47(4): 589-606. 
25. Smith J R, Terry D J, \& Manstead A, et al. 2007. Interaction Effects in the Theory of Planned Behaviour: The interplay of Self-Identity and Past Behaviour. Journal of Applied Social Psychology, 37(11): 2726-2750.

26. Steenhaut S, \& Van Kenhove P. 2006. The mediating role of anticipated guilt in consumers' ethical decision-making. Journal of business ethics, 69(3): 269-288.

27. Tangney J P. 1999. The Self-Conscious Emotions: Shame, Guilt, Embarrassment and Pride. Handbook of cognition and emotion, 541-568.

28. Tangney J P, Stuewig J, \& Mashek D J. 2007. Moral emotions and moral behavior. Annual review of psychology, 58: 345-372.

29. Taylor S A, Ishida C, \& Wallace D W. 2009. Intention to engage in digital piracy. Journal of Service Research, 11(3): 246-262.

30. Todd J, \& Mullan B. 2011. Using the theory of planned behaviour and prototype willingness model to target binge drinking in female undergraduate university students. Addictive Behaviors, 36(10): 980-986

31. Van der Pligt J, Zeelenberg M, \& Van Dijk W W, et al. 1997. Affect, attitudes and decisions: Let's be more specific. European review of social psychology, 8(1): 33-66.

32. Wang X, \& Mcclung S R. 2013. The immorality of illegal downloading: The role of anticipated guilt and general emotions. Computers in Human Behavior, 28(1): 153-159.

33. Wang Y S, Lin H H, \& Luarn P. 2006. Predicting consumer intention to use mobile service. Information Systems Journal, 16(2): 157-179.

34. Wood R T A, Griffiths M D, \& Parke A. 2007. Experiences of time loss among videogame players: An empirical study. Cyber Psychology \& Behavior, 10(1): 38-44. 